\title{
JOSUÉ DE CASTRO: CIÊNCIA E LITERATURA OU DOIS RIOS QUE SE ENCONTRAM NA CIDADE DO RECIFE
}

\author{
Jose CARLos Milleo ${ }^{1}$ \\ Universidade Federal Fluminense
}

\begin{abstract}
Resumo: Josué de Castro, além de notável geógrafo e médico, incursionou também no campo das letras, chegando inclusive a produzir contos, um romance e até mesmo um livro infantil em parceria com Cecília Meireles. Também é digno de nota o estilo inigualável de seus textos científicos, que nunca abandonaram uma afinidade muito grande com a estética e o cuidado com a escrita, habilitandonos a afirmar que por vezes ciência e arte se confundem em seus estudos. O presente trabalho, ao explorar a produção de Josué de Castro como um expoente da Geografia que sofreu forte influência das matrizes francesas e notadamente da figura de Vidal de la Blache, busca avaliar em que medida a produção do escritor ajudou a erigir também o edifício de suas ideias científicas e de que forma é possível aproveitar as incursões de Josué no campo da Literatura no sentido de decantar alguns procedimentos metodológicos que bem podem ajudar na constituição de uma Geografia que se habilite ao desvendamento da realidade concreta.

Defenderemos aqui que, ao estabelecer uma convivência entre o escritor e o cientista numa trajetória original, Josué acaba repercutindo e levando a proposta geográfica francesa para um patamar igualmente inédito. Esta relação é fator determinante para que possamos pensar em Josué de Castro não como uma eminência já superada, ainda que digna de relevo, mas como o detentor de uma proposta metodológica altamente habilitada a ser aplicada na atualidade.
\end{abstract}

Palavras-chave: Josué de Castro. Geografia. Literatura. Descrição.

\section{JOSUÉ DE CASTRO: SCIENCE AND LITERATURE OR TWO RIVERS THAT CONVERGE IN THE CITY OF RECIFE}

Abstract: Josué de Castro, as well as a notable geographer and doctor, also ventured into the field of letters, even producing stories, a novel and even a children's book in partnership with Cecília Meireles. It is also noteworthy the unequaled style of his scientific texts, which have never abandoned a great affinity with aesthetics and care for writing, enabling us to affirm that sometimes science and art are

\footnotetext{
${ }^{1}$ Professor do Departamento de Geografia da Universidade Federal Fluminense (UFF). Contato: josemilleo@id.uff.br
} 
mixed in their studies. The present work, exploring the production of Josué de Castro as an exponent of the geography that was strongly influenced by the French matrixes and notably of the figure of Vidal de la Blache, seeks to evaluate to what extent the writer's production helped to erect the building of His scientific ideas and how it is possible to take advantage of the incursions of Josue in the field of literature in order to decant some methodological procedures that may well help in the constitution of a geography that is enabled to unravel the concrete reality. We will defend here that, in establishing a coexistence between the writer and the scientist in an original trajectory, Josué ends up repercussing and taking the French geographical proposal to an equally unprecedented level. This relationship is a determining factor so that we can think of Josué de Castro not as an eminence already overcome, although worthy of note, but as the holder of a methodological proposal highly enabled to be applied in the present time.

Keywords: Josué de Castro. Geography. Literature. Description.

\section{Introdução}

Num livro editado em 2002, o geógrafo Carlos Augusto de Figueiredo Monteiro já se colocava diante da questão de uma persistência, a constância de um mútuo olhar ou, diríamos inclusive, de um flerte entre a Geografia e a Literatura. Com bastante propriedade, dado seu envolvimento com o tema, este autor apontava que naquele momento, quando já se poderia dar por completamente abandonada a perspectiva de saborearmos a evocação lablacheana à personalidade das paisagens e regiões, emergia renovado esforço de aproximação entre as duas perspectivas de abordagem dos lugares e de seu povo. Esta constatação de fato intriga, já que um e outro prisma foram mantidos afastados dentro do âmbito da modernidade. Para a Geografia ficara reservado o entendimento racional e crítico do espaço, esquadrinhado, recortado e finalmente recomposto segundo a ótica e os preceitos mais insuspeitos da Ciência. A Literatura, como bem assinala Marandola (2010), ficou em outra "gaveta". Em que pese o fato de esta nunca ter abjurado, por princípio, à racionalidade e muito menos à criticidade, é certo que a ela ficou reservado o reino do abstrato e do estético.

Depreendemos igualmente dos dois apontamentos, acima destacados, duas questões diversas, mas ao mesmo tempo intimamente ligadas: em primeiro lugar, ganha relevo o sentimento de insatisfação da forma como a modernidade tem enquadrado algumas questões atinentes às Ciências Humanas. Se durante um bom tempo a vigência dessa atmosfera, chamemo-la de moderna, foi garantida pela convicção na suficiência que o casamento da racionalidade técnica e a Ciência estabeleciam no sentido de assegurar o progresso humano, agora restam poucos entre aqueles que postam os dois pés firmemente em tais convicções. Aliás, a própria confiança na ideia de progresso já experimenta sua crise particular (NISBET, 1980; DUPAS, 2006), e isso de modo algum é fenômeno tão recente. 
Não é nosso objetivo referendar o argumento de que estaríamos já dentro de uma nova fase, a superação da modernidade (LYOTARD, 1979) ou a própria exacerbação de seu conteúdo como nos colocam autores como Guiddens (1994), ou Habermas (1968). Antes aproveitaremos estas constatações de Monteiro e Marandola como um claro demonstrativo de que a racionalidade instrumental (WEBER, 1896), típica de nossos dias, já não preenche as expectativas de cobrir o amplo arco de questões atinentes às Ciências Sociais. Como bem constata Milton Santos, seria ingênuo negar um processo que:

após haver (sucessivamente) atingido a economia, a cultura, a política, as relações interpessoais e os próprios comportamentos individuais, agora (...), estaria instalando-se no próprio meio de vida dos homens, isto é, no espaço geográfico. (SANTOS, 1996, p. 310).

Por outro lado, não seria menos pueril creditar a esta mesma racionalidade o caminho único e perfeito de compreensão do espaço que se desenha (ainda que) sob sua égide. Alerta este autor acertadamente que, muito embora o momento ora vivido sinalize para uma expansão da racionalidade capitalista rumo ao ilimitado:

ao mesmo tempo, e felizmente (esta realidade) aponta para a possibilidade da construção de um novo sentido, a partir justamente da elaboração de contrarracionalidades que a análise geográfica revela nos comportamentos atuais do campo e da cidade. (op. cit., p. 310)

A segunda conclusão refere-se à diversidade de caminhos que se abrem quando o que se pretende é estabelecer uma resposta a essa atmosfera de desencanto. Alguns, por exemplo, irão enveredar pela revisão dos conceitos já plenamente estabelecidos, tentando lhes conferir novo frescor, por assim dizer. Cremos que um caso clássico é o que se passa no âmbito da categoria trabalho que suscita novo enquadramento para sua compreensão ${ }^{2}$. Outra categoria, recentemente adicionada ao debate geográfico, é o cotidiano, cujo percurso empreendido por alguns cientistas sociais recoloca a necessidade de sua análise agora desprovida do preconceito que a empurrou para o âmbito do desimportante, do inescrutável ou mesmo do redutível. No âmbito da Sociologia, por exemplo, há uma busca por posicionamentos que não desmereçam esta categoria ao vê-la como uma antítese às grandes estruturas sociais e processos históricos, mas antes revendo seu sentido nessa mediação, recolocando, por exemplo, o visível e o aparente como algo importante no âmbito de tais análises (MARTINS, 2014).

\footnotetext{
${ }^{2}$ Sobre esta revisão, ver a crítica de Ricardo Antunes (2007) a autores como Gorz e Habermas.
} 
O trabalho aqui proposto trafega pela vereda explicitada logo no primeiro parágrafo e, portanto, tenta estabelecer uma ligação entre estas duas modalidades de insatisfação. Rejeita por um lado a estreiteza do raciocínio que argumenta da antítese entre o que é científico e racional e o âmbito do sensível, do alegórico, ainda, é claro, que isso signifique a adoção de um caminho perigoso, já que é pouco trafegado pela Geografia e, portanto, apresenta reduzidos pontos mais luminosos e firmes ao apoio. Da mesma forma, recusa também o argumento de que isso signifique a circunscrição de uma ciência preocupada quase que com o particular, o único, o individual e, mais ainda, com o frugal e cosmético, resultando, portanto e por princípio, em algo distanciado da própria perspectiva de prática científica. No caso específico do estudo aqui proposto, estamos colocando que certa parcela do manancial romanesco pode significar um novo caminho na resolução de tais impasses, senão em sua totalidade ao menos contribuindo para o estabelecimento de um novo patamar nas discussões, um novo ponto de vista sobre dilemas dos quais a prática de pesquisa não tem conseguido se desenredar.

Para que essa atmosfera seja realmente oxigenada, escolhemos um autor que enveredou profundamente por caminhos que, ao rejeitar os raciocínios obtusos anteriormente explicitados, acabou por nos fornecer pistas valiosas para uma conjunção colaborativa entre a pesquisa científica e a atividade literária. Josué de Castro, acreditamos, logrou esse êxito como pouquíssimos. Frisamos essa qualificação, destacando-o dentre um pequeno número, por uma razão tão simples quanto evidente: Josué foi um dos raros geógrafos que transpôs por larga margem os limites entre a Ciência e a Literatura. Isso se deu não só por conta de uma redação científica que em diversos casos se aproxima admiravelmente da criação romanesca, mas também (e talvez principalmente) porque Josué incursionou nos terrenos da Literatura. Em sua biografia este autor ousou escrever livros que mesclavam supreendentemente Ciência e Literatura (tal como Documentário do Nordeste, de 1937), que, atendo-se ao exclusivamente científico, não abdicaram do sensível (como em Um ensaio de geografia urbana: a cidade do Recife, de 1948) ou que se aventuraram por completo nas águas da Literatura (como em Homens e caranguejos, de 1967).

\section{Josué de Castro e a relação entre Ciência e Literatura}

Partimos então das seguintes questões: deveríamos observar o recurso à composição literária, assumido por Josué de Castro, como apenas um aditivo provindo de um percurso que lhe permitiu o uso mais refinado da palavra? Seria apenas uma idiossincrasia, uma característica especifica de Josué e, sendo apenas dele, passível de ser tratada como mera curiosidade característica do cientista? 
Teríamos aí uma postura que advoga da necessidade de atentarmos à sua temática, como tradicionalmente tem sido feito, e não para a metodologia que fez uso da exposição literária à moda de uma lupa que o auxiliou a estabelecer um jogo de escalas, onde se alterna a análise da estrutura e a narrativa do detalhe do modo de vida e da natureza de seu objeto de consideração. Advogaremos aqui, portanto, que Josué de Castro não foi premonitório e inovador apenas na temática escolhida, notadamente a temática da fome, mas foi também um autor que muito poderia nos ajudar se atentássemos igualmente à sua metodologia, especificamente quando examinamos mais amiúde seu persistente recurso a uma maneira literária de explorar seu objeto de pesquisa e expor seu ponto de vista. Na verdade, um e outro recurso - o manuseio competente da palavra escrita na composição de paisagens e seu esgrimir como ferramenta metodológica - se misturam e se alimentam, permitindo que possamos realizar uma distinção meramente didática e nunca evidente na prática.

De maneira análoga, o núcleo deste trabalho oscila, então, entre duas posturas que nunca se distinguem por completo: buscamos dar relevo à maneira, digamos assim, literária com a qual Josué explora e expõe os resultados de suas pesquisas; ao mesmo tempo analisamos como este recurso configura uma sinergia tão densa entre Ciência e Literatura que acaba servindo de solo firme para as críticas e conclusões do autor. Deste modo estamos argumentando a respeito de uma metodologia passível de ser utilizada por qualquer pesquisador e não apenas àqueles mais afeitos às letras e ao manuseio mais hábil da palavra escrita. Propomos aqui, finalmente, a experiência da fluência da escrita de Josué, mas, sobretudo, decantaríamos um procedimento passível de ser expandido e assumido por aqueles interessados em adotar percursos correlatos ou similares.

Onde podemos chegar mediante o exame proposto? Cremos que um saldo bastante interessante pode ser num primeiro momento o da revitalização do expediente à descrição pela ciência geográfica. Associada à geografia tradicional e, portanto, dada como recurso superado na contemporaneidade, a revisão desta metodologia presente em Josué de Castro, seu recurso à descrição, talvez possa recolocar, agora sem tantos preconceitos, a importância de tal procedimento. Essa descrição, em primeiro lugar, faz parte de uma tradição que o próprio Josué faz questão de ressaltar quando remete suas bases metodológicas a figuras da escola francesa como Vidal de la Blache, Jean Brunhes, Max Sorre ou Pierre Monbeig (Castro, 1959). Aliás, René Clozier (1943), ao analisar o processo de trabalho de La Blache, chega a frisar que essa tradição é responsável por uma identidade forte dos textos geográficos com o romance regionalista, embora ressalve que um e outro não possam ser confundidos. Num apontamento que define com rara precisão o metiê geográfico, Clozier acrescenta:

Ao mesmo tempo, porém, esta descrição é selectiva; elimina certos traços e junta outros, pois no fundo ela orienta-se segundo 
um determinado pensamento. É uma descrição científica e, por consequência, esquematiza. (CLOZIER, 1943, p. 119).

O destaque dado por este à descrição geográfica adiciona grande relevo a tal atividade e lhe confere o caráter científico na medida em que só se pode filtrar dentre os elementos da paisagem aqueles que realmente interessam, através de sua contraposição aos conceitos já preestabelecidos e que, ao mesmo tempo, guiam o pensamento na busca de traços que confirmem ou desqualifiquem uma explicação.

Contudo, observar Josué de Castro tão somente como um autor que se filia ao pensamento exposto acima apenas arranha o caso específico de sua forma de abordagem, na medida em que o vincula a um importante passado da Geografia, mas arrefece bastante a possibilidade deste autor ser decisivo na abordagem da atualidade. Mediante este encaminhamento, sua metodologia ganha a importância muito à moda de um acervo de museu, algo para ser admirado, vez por outra até lustrado para se lhe retirar a poeira. Apenas isso. Definitivamente, este não é o enquadramento das ideias de Josué de Castro defendido aqui. Na verdade, o processo seletivo, advogado por Clozier (op. cit.), é aperfeiçoado e levado às últimas consequências por Josué de Castro na medida em que o leque de informações colhidas e dispostas ao autor é bastante enriquecido, pois não descarta nenhuma possibilidade de composição do espaço urbano recifense. Notemos na passagem a seguir como a aproximação a Recife dá-se com o autor buscando lançar mão de praticamente todos os sentidos humanos, na composição da paisagem da cidade pernambucana.

O Recife é todo esse mosaico de cores, de cheiros e de sons. Nesse desadorado caos urbano confuso da fusão violenta de várias expressões culturais, só uma coisa tende a dar um sentido estético, próprio à cidade. A absorver e anular os efeitos e os contrastes desnorteadores, dando um selo inconfundível à cidade. É a paisagem natural que a envolve. O seu mundo circundante com seus acidentes geográficos e sua atmosfera sempre em vibração, varada por todos os sentidos pelos reflexos intensos da luz sobre as águas. (CASTRO, 1938, p. 16).

Estaríamos então diante de uma proposta que não apenas se apresenta como emblemática de seu tempo, mas que contém cartas de naipes ainda maiores para serem postos na mesa. Este é um recurso que, a nosso ver, clama por atenção, pois não apenas recoloca o papel do visível (e, por conseguinte, do sensível) nesta composição, assim como redefine a ações do pesquisador diante de seu objeto. $\mathrm{Na}$ compreensão de Josué este visível não é coadjuvante ou mesmo obstáculo atrás do qual poderiam estar ocultas as relações sociais que o engendraram, mas um ator que 
estabelece logo de início a exigência de colocar a percepção do geógrafo no cerne do estudo do espaço, neste caso, urbano.

Assim é que a visão, ferramenta basilar no estabelecimento e na análise de qualquer paisagem, recebe sofisticado tratamento na medida em que a ela são adicionados também os aportes passíveis de serem obtidos a partir dos diferentes ângulos em que o observador se coloca. Não estamos falando aqui de mera moldura que se serve ao pensamento, como corriqueiramente a faculdade da visão costuma ser tratada em certa parcela da produção geográfica, mas de um desvelamento que principia a partir de uma interrogação bastante original feita à paisagem: como se poderiam captar as nuanças e a personalidade de cada espaço urbano? Responde-nos Josué, oferecendo-nos o caminho das pedras:

há cidades feitas para serem contempladas de baixo para cima: do nível do mar como New York, Rio e Bahia; ou das tenebrosas profundidades dos vales, como Tasco ou Granada. São cidades construídas para serem admiradas por forasteiros, de rostos embevecidos e levantados na direção das nuvens. Já outras cidades se mostram em sua plenitude quando olhadas em seu próprio nível: Paris, quando interrogada por olhares amorosos lançados do seu próprio centro em todas as direções, e Chicago, vista das distantes águas do lago, projetada sua monumentosa massa arquitetônica contra a linha esculpida no horizonte. (CASTRO, 1938, p. 154).

E prossegue o autor explorando o território do sinestésico, mas desta vez retomando-o a serviço do desvendamento da capital pernambucana:

O Recife, como qualquer outra cidade, apenas se deixa penetrar em sua essência ou consente em revelar o sentido de sua alma aparentemente dispersa nos contrastes da paisagem, por um determinado ângulo visual. (op. cit., p. 155)

Deste modo, ousamos constatar que esta busca pela absoluta exploração do sensório assume uma radicalidade em Josué de Castro que por vezes beira o erotismo, dado seu fascínio pelo estudo do urbano. Para o autor em tela, à moda de uma mulher, Recife só se deixa capturar pelos que porventura apurarem os ouvidos de modo a compreender seus sons, aguçarem suas pupilas para admirar suas cores, acordarem seu olfato para perceber seus cheiros, enfim, colocarem toda sua sensibilidade a serviço da percepção das dimensões de uma cidade que:

(...) só se deixa captar na unidade de sua expressão urbana, quando vista do alto dos aviões em sua perspectiva vertical. É das alturas das nuvens que se recebem todos os eflúvios de sua poesia 
urbana, subindo violentamente através da atmosfera varada em todos os sentidos pelos reflexos da luz sobre as águas. (op. cit., p. $155)$.

Documentário do Nordeste foi escrito em 1937. Dez anos depois, os ecos ou, melhor ainda, o saldo desta opção fica bem mais claro. Em 1948 é publicado Um ensaio de geografia urbana: a cidade do Recife, livro escrito para o ingresso de Josué na cátedra de Geografia Humana na Universidade do Brasil ${ }^{3}$. Na obra que percorre os "fundamentos fisiográficos", a "ocupação humana" e a "fundação da cidade", Josué entrecruza os rios que cortam Recife, os solos que estes ajudaram a formar e, por fim, a cidade erigida sobre eles, solicitando o mesmo cuidado no ângulo de observação de tal cenário:

foi nesses bancos de solo ainda mal consolidado - mistura ainda incerta de terra e de água - que nasceu e cresceu a cidade do Recife, chamada de cidade anfíbia, como Amsterdã e Veneza, porque assenta as massas de sua construção quase dentro da água, aparecendo numa perspectiva aérea ${ }^{5}$, com seus diferentes bairros flutuando esquecidos à flor das águas. (CASTRO,1959, p. 167).

Assim, cremos que seguramente estamos diante de um encaminhamento digno de cuidadosa consideração, já que representa uma forma bastante aperfeiçoada da concepção vidaliana de pesquisa geográfica. Podemos argumentar neste sentido a partir da própria metodologia contida e proposta por Vidal, esta sim passível de ser identificada entre outras características, a partir do valor dado à descrição como procedimento de trabalho.

A Geografia distingue-se como ciência essencialmente descritiva. Não que renuncie à explicação: o estudo das relações dos fenômenos, de seu encadeamento e de sua evolução, são também caminhos que levam a ela. Mas esse objeto mesmo a obriga, mais

\footnotetext{
${ }^{3}$ Este trabalho foi intitulado, no exame de cátedra, como Fatores de localização da cidade do Recife. Posteriormente, em 1956, o mesmo trabalho foi publicado como A cidade do Recife: um ensaio de geografia urbana (Editora Casa do Estudante). Em 1957, o mesmo estudo é incluído como um capítulo de Ensaios de geografia humana (Editora Brasiliense) e revisado pelo autor na segunda edição de 1959. É esta edição que, por sua vez, serve como referência para a publicação pela Fundação Joaquim Nabuco de Um ensaio de geografia urbana: a cidade do Recife, em 2013, e que aqui utilizamos como texto-base.

${ }^{4}$ Basicamente, é esse o sumário do livro.

${ }^{5} \mathrm{Na}$ altura deste itálico, que não é do autor, inserido por nós para frisar a expressão, é preciso também esclarecermos que esta parte do estudo se inspira no excelente trabalho da professora Teresa Sales, que em recente livro nos convida a uma reflexão sobre o capítulo "A perspectiva ideal de uma cidade", contido em Documentário do Nordeste. Na verdade, Sales propõe um interessantíssimo paralelo deste capítulo com o poema "De um avião", de João Cabral de Melo Neto (SALES, 2014).
} 
que em outra ciência, a seguir minuciosamente o método descritivo. (LA BLACHE, 1913, p. 45).

Ao argumentar da existência de uma epistemologia contida em La Blache, Ribeiro (2010) destaca o papel da descrição e do "olho de geógrafo" que lhe seria pré-requisito. A explicação dos fenômenos, contudo, apesar de constituir o cume de um processo iniciado a partir deste olhar, estaria tanto mais apta a estabelecer-se quanto mais enriquecido fosse esse ato. Esta sofisticação do ato de olhar, por sua vez, qualifica a explicação para capturar a complexidade dos fenômenos e, para o caso de Josué de Castro, converte a descrição também num processo de descoberta, já que supõe o trabalho de campo cujo estofo é igualmente complexo. Em Josué de Castro, como vimos, os sentidos humanos põem-se a serviço da captura dessa complexidade.

Contudo, ao propor uma descrição geográfica que seja "maleável e variada como seu próprio objeto", La Blache (op. cit.) nos fornece novas pistas na análise da proposta de Josué de Castro para esta mesma ação. Para La Blache pode ser interessante que o pesquisador se sirva da terminologia popular, uma vez que, sendo esta formada diretamente de um contato entre a natureza e quem a profere, pode ampliar as conexões para além dos limites do contato mais resumido do pesquisador com o espaço estudado. Conforme La Blache propõe, uma "máxima rural ou um provérbio podem abrir uma luz sobre um relatório", contar-nos de determinada periodicidade ou das coincidências de um fenômeno, enfim, "qualquer coisa que se reclama diretamente da Geografia" (op. cit., p. 46).

Voluntária ou involuntariamente, fato é que, no prefácio a Homens $e$ caranguejos, Josué mais uma vez toma partido das indicações lablacheanas quando se refere ao modo como o povo fala e seu revelador vocabulário. Vemos ali naquele preâmbulo como "a descoberta da fome", descrita por Josué, tem na prosa do povo uma importante via para os insights que acabaram conduzindo-o à sua obra máxima:

Fui compreendendo que toda a vida dessa gente girava sempre em torno de uma só obsessão - a angústia da fome. Sua própria linguagem era uma linguagem que quase não fazia alusão a outra coisa. A sua gíria era sempre carregada de palavras evocando comidas. As comidas que desejavam com desenfreado apetite. A propósito de tudo se dizia: é uma sopa, é uma canja, é um tomate, é uma ova, é um abacaxi, é uma batata, é pão-pão, é queijoqueijo. Era como se esta gíria fosse uma espécie de compensação mental de um povo sempre faminto. (CASTRO, 1967, p. 4).

\footnotetext{
${ }^{6}$ Expressão destacada por Ribeiro (2010) em autores como La Blache e Jean Brunhes.

${ }^{7}$ Este é o título do prefácio reapresentado numa coletânea feita por sua filha Ana Maria Castro em 1983.
} 
Nesse périplo Josué não se desfez das lembranças das histórias de seu pai, dos relatos de velhos negros ex-escravos guardados nas memórias de sua juventude, recorrendo até mesmo aos cantadores do bumba-meu-boi na zona dos mocambos de Recife. Todos ministrando "um curso inteiro sobre a fome" (op. cit.), um curso que mais tarde seria resgatado por completo em cada uma de suas obras.

Dada a conduta defendida por Josué em seus trabalhos de campo ${ }^{8}$, despida de preconceitos tanto na valorização da cultura popular quanto na atitude mais aberta em relação às fontes de informação para a síntese de suas ideias, não é de se estranhar seu alinhamento às correntes de pensamento que igualmente viam em muitos aspectos dessa cultura as respostas aos dilemas da própria população. Assim como La Blache, Josué está aberto e disposto à interação com aqueles que constituem seu objeto de estudo confiando numa postura que, pode-se dizer, não só está em consonância com a sociologia que viria a chefiar a pesquisa social nos anos 1930, provinda da Escola de Chicago nos Estados Unidos, como em diversos momentos parece ultrapassá-laquando radicaliza esta aposta de vanguarda. Para este caso um eloquente exemplo pode ser captado a partir da postura de Josué de Castro em relação à questão da necessidade de erradicação dos mocambos que compunham a paisagem dos mangues de Recife, conforme esta era defendida por parcela expressiva do pensamento científico e político da época. Josué, como veremos aqui, estabelece um debate que é bastante condescendente com essa arquitetura, que abrangia largas extensões do espaço urbano recifense.

Não é nosso objetivo, no estudo ora proposto, colocar em pauta os acertos ou os erros de Josué ao assumir tal posicionamento. A questão aqui é utilizarmos essa postura como um caminho que facilita a prospecção do pensamento josuelino na medida em que ilustra muito claramente seu modo de acolher e aproveitar-se, no melhor sentido que a palavra possa ter, daquilo que a sabedoria popular havia acumulado, estabelecendo uma parceria muito similar ao que Paul Claval (2010) fala quando nos adverte que "desde a origem dos tempos, todo homem é um geógrafo" e que ele segue o sendo até hoje. Em outras palavras, o universo científico não está apartado da vida dos homens e de seus saberes, de suas atitudes e habilidades, enfim, dos conhecimentos que acumularam como resposta aos seus dilemas, por mais corriqueiros ou ingênuos que possam nos parecer. Claval, pelo contrário, defende que a Ciência acaba sendo o vetor resultante "das experiências renovadas e de procedimentos imaginados pelos homens para responder aos imperativos de sua vida cotidiana" (op. cit.), da busca por um sentido às suas vidas e do anseio por saberem que acontece para além de seus horizontes. Conclui Claval

\footnotetext{
${ }^{8}$ Para Manuel Correia de Andrade (2003), o pensamento de Josué de Castro se estruturou em uma dupla fonte: "teórica por meio do estudo e da leitura de autores clássicos tanto nas ciências biológicas como sociais, e na prática, mediante a observação de campo e pesquisas diretas, por ele organizadas e dirigidas" (p. 74 e 75).
} 
com um raciocínio que se encaixa perfeitamente aos procedimentos de Josué de Castro: "as Ciências Sociais criticam os saberes empíricos, os sistematizam, ampliando ou revolucionando-os, mas estão enraizadas no mesmo fundo de necessidades e curiosidades" (op. cit., p. 11).

Antes de prosseguirmos em nossa análise, porém, cumpre que tenhamos claras as circunstâncias dentro das quais Documentário do Nordeste foi escrito: para o filósofo Michel Zaidan Filho (2003) essa visão, digamos, quase romântica que Josué reserva aos mocambos tem sua explicação no momento histórico dentro do qual estão estabelecidos os debates sobre o processo de modernização empreendido pelo Estado Novo no Nordeste. Ainda conforme Zaidan, Josué de Castro se situa dentro do que se poderia considerar como uma "geração regionalista do Nordeste". Altamente crítica a tal modernização, esta geração se organizou na década de 1920 em torno da figura magnética de Gilberto Freyre. Está em curso, neste momento, um processo composto por mudanças de ordem política, econômica, cultural, social que recoloca o papel do espaço nordestino dentro da realidade brasileira, e esta recomposição acaba estabelecendo tensões que se traduzem nos campos literário e científico e que resultam neste movimento regionalista dentro das cercanias nordestinas, um movimento ao qual uma parcela significativa da produção de Josué de Castro está ligada. Este movimento regionalista acaba tentando recompor a ideia de Brasil a partir da própria ideia de Região Nordeste, e por decorrência se opõe à outra corrente identificada com o processo de modernização, com a urbanidade e o industrialismo "dos modernistas de São Paulo" (op. cit.).

Gilberto Freyre, ao descrever as habitações dos caboclos, não poderia ser mais ilustrativo do pensamento da corrente que ele mesmo capitaneava, na sua visão estes mocambos:

surgem aos nossos olhos como uma doçura de povoações de ilhas do Pacífico - as mais romantizadas pelos viajantes, pelos poetas e até pelos antropologistas. $\mathrm{O}$ seu ar é o das casas inteiramente à vontade entre as palmeiras e a beira-mar ou da água doce. (FREYRE, 2000, p. 30).

Josué de Castro é consoante com o pensamento de Freyre. Na primeira parte do livro Documentário do Nordeste, constituída de contos e descrições ${ }^{10}$, embora o autor caracterize que a plenitude deste tipo de habitação represente também a permanência de "verdadeira senzala remanescente fracionada em torno das casasgrandes da Veneza Americana" (CASTRO, 1937), também edulcora a paisagem

\footnotetext{
${ }^{9}$ Dentro da corrente fortemente crítica ao regionalismo nordestino, Zaidan Filho (2003) ainda encaixa figuras como João Cabral de Melo Neto, Graciliano Ramos, Raquel de Queiroz, José Lins do Rego, além de figuras do mundo da política como Agamenon Magalhães.

${ }^{10}$ É denominada essa primeira parte de "Paisagem viva do Nordeste".
} 
com a atmosfera reinante: "Poesia primitiva de negros e mestiços fazendo xangô e cantando samba. Fisionomia africana" (op. cit.).

Já na segunda parte, ainda que numa redação mais "fria", Josué persiste nesta defesa apontando que o mocambo, "em sua expressão mais elementar, reúne até, como recinto habitável, uma boa dose de qualidades higiênicas, fruto da experiência das populações primitivas do Nordeste" (CASTRO, 1937). Como já frisamos anteriormente, não interessa aqui pôr em debate essa defesa ou até mesmo a forma estabelecida pelo autor em tela de encaminhá-la. Fosse esse o caso, poderíamos passar por cima de outro aspecto interessante na mecânica da argumentação de Josué. No trecho aqui destacado, desta vez, a defesa é realizada a partir de uma arguta observação das condições nas quais vive a população habitante dos mangues:

Se esta disposição especial das paredes, tanto externas como internas, não alcançando a cobertura, constitui uma solução curiosa do problema da ventilação, a cobertura de palha ou capim também constitui um admirável meio de defesa contra o excesso de calor. (CASTRO, 1938, p. 73)

Assim, a crítica à modernidade homogeneizante, advinda da aquisição de novas tecnologias e da expansão da urbanidade, não se reveste de um discurso anacrônico e saudosista, mas, antes, se calça exatamente na observação atenta da sabedoria do povo e, mediante esse procedimento, lhe depura o que tem de mais rico, que é a capacidade de adaptação e aproveitamento das condições oferecidas pelo meio ambiente. Neste sentido podemos afirmar que o próprio conceito do que seja "o moderno" é alvo de cortante reflexão:

A substituição da habitual cobertura de palha por uma de zinco constitui uma dessas inovações que traduzem prosperidade. Mal aplicada prosperidade, que em lugar de melhorar, vem piorar e de muito, as condições higiênicas do mocambo"(...) O zinco é ótimo transmissor do calor, material especialmente feito para transformar o mocambo fresco numa verdadeira estufa. (op. cit., p. 73).

Ao final da consideração sobre o "problema" dos mocambos, Josué de Castro resume de forma admirável e mostra como seu trabalho de campo foi criterioso colhendo informações advindas de diversas fontes. Josué pontua que uma solução apressada tem grande chance de fracasso, uma vez que resultaria na construção de casas mais assemelhadas a gaiolas, "verdadeiras assadeiras em série, com material impróprio, disposição arquitetônica em desacordo com as condições do meio (como a maioria das vilas operárias, construídas entre nós)" (op. cit.); e onde a população contaminada e subnutrida do Nordeste teria potencializadas suas péssimas condições 
de existência. Mais tarde, em seu exame de cátedra, novamente ao analisar Recife, a reflexão sobre os mocambos é retomada e o autor em questão continua nos demonstrando que persiste sua preocupação com a técnica provinda daqueles que nada possuem mas, talvez justamente por isso, têm muito a ensinar. Refletindo sobre o processo de expansão da cidade por sobre as áreas alagadas, o autor ressalta o papel dos mocambos para o trabalho de aterro e drenagem destas regiões, originariamente ocupadas pelas águas parcialmente ou na totalidade dos dias do ano (Castro, 1959). Sua descrição se atém ao fato de que, para a construção de sua habitação nas zonas sujeitas às inundações, o caboclo frequentemente costuma elevar o nível do solo, construindo pequenos montes artificiais muito à moda do que os holandeses já faziam nas terras baixas, os terpen. Assim, este autor chega mesmo a se perguntar se essa técnica não teria sido aprendida pelos caboclos constituindo mais um traço da ocupação holandesa em Pernambuco (op. cit.).

É interessante perceber, neste ponto, como o encadeamento das ideias de Josué de Castro acaba nos obrigando a tomar o fio condutor de seu pensamento e, antes dele, seu método de coleta das respostas com as quais acabava se deparando no campo. Deste modo vamos percebendo que estes procedimentos de trabalho, embora possam ser tidos como superados, na verdade, quando examinados mais amiúde, vão ganhando uma atualidade que tem rara possibilidade de comparação na produção geográfica brasileira. $\mathrm{O}$ caso da abordagem da relação entre homem e meio ambiente talvez seja um destes flancos onde reina bastante concordância entre os autores que esmiúçam a produção do geógrafo pernambucano. Num paralelo bastante interessante à produção de Max Sorre, Josué infunde uma perspectiva, nas suas próprias palavras, ecológica aos estudos sobre a fome. Conforme Mançano e Porto-Gonçalves (2000) assinalam, nesta perspectiva "observamos o conjunto dos conhecimentos de Josué, que rompe com uma visão economicista e reducionista e expressa na visão interativa entre as pessoas e o espaço geográfico que habitam". Numa parcela da obra de Josué, também destacada pelos autores acima citados, temos esse enfoque bastante evidenciado:

pelos princípios fundamentais da ciência geográfica, cujo objetivo básico é localizar com precisão, delimitar e correlacionar os fenômenos naturais e culturais que ocorrem à superfície da terra. (...) Por outras palavras procuraremos realizar uma sondagem de natureza ecológica, dentro desse conceito tão fecundo de 'Ecologia', ou seja, do estudo das ações e reações dos seres vivos diante das influências do meio. (CASTRO, 1946, p. 24-25).

Basicamente, o processo de descoberta da fome, já destacado anteriormente, tem seu cume na engenhosa interação que Josué estabelece entre homem e meio ambiente valendo-se de um enquadramento que tem contribuições provindas da economia e da sociologia, mas também da biologia. É através da interação entre 
cada uma destas contribuições que Josué irá considerar a questão da fome de uma maneira inédita pela Geografia.

Nenhum fenômeno se presta mais para ponto de referência no estudo ecológico destas correlações entre grupos humanos e os quadros regionais que eles ocupam do que o fenômeno da alimentação - o estudo dos recursos naturais que o meio fornece para a subsistência das populações locais e o estudo dos processos através dos quais essas populações se organizam para satisfazer as suas necessidades fundamentais de alimentos. (op. cit., p. 25).

E é justamente mediante a amplitude da abordagem propiciada pela Geografia que Josué cunha dois conceitos basilares à sua abordagem: fome epidêmica e fome endêmica. No Nordeste dominado pelo semiárido, ou o "sertão" como o denomina, de solos pobres e clima quente com chuvas escassas e irregulares, predomina a fome epidêmica ou a fome aguda e violenta, a fome que o senso comum acabou por associar a todo o Nordeste. Já no Nordeste do Açúcar ou a Zona da Mata, Josué descobre uma outra fome, a fome endêmica, oculta porque parcial, caracterizada pelo baixo consumo de proteínas, calorias, sais minerais e carboidratos. Uma fome impensável e dispensável, pois não estava associada às condições de produção, haja vista que solos ricos e com água em quantidade o próprio colonizador português já havia constatado que abundavam na região.

Essa perspectiva ecológica não nasce em Geografia da fome, senão vai sendo aperfeiçoada continua e persistentemente. Nosso objetivo ao ressaltá-la, longe de tentar repisar uma parcela já considerada à exaustão por outros autores, é enfatizar o papel fecundador que a reflexão de cunho mais descritivo, mais aberto à contemplação eivada de sensibilidade, acabou infundindo ao pensamento de Josué de Castro, propiciando-lhe tais insigths. Já em Documentário do Nordeste (1937), portanto bem antes de Geografia da fome (1946), essa interação entre homem e meio é caracterizada na porção, digamos assim, mais literária da obra. Encaixado na primeira parte (ou "Paisagem viva do Nordeste"), o Ciclo do caranguejo é o relato da vida de uma família que mora nos mangues de Recife. A descrição que Josué faz da fuga da família Silva, originária do sertão, escapando como pode da seca e da fome no Cariri passando pelas terras ocupadas pelas usinas de cana para, finalmente, à moda do Capibaribe, desaguar e se fixar nos mangues de Recife, pode bem nos demonstrar a função que este encaminhamento possuiu no pensamento do geógrafo. Josué consegue capturar, com rara capacidade, a lógica que orienta o pensamento desta família fazendo girar o enredo em torno da ideia de "paraíso", agora finalmente encontrado depois da saga vivida: 
Começou o arrocho. Só havia uma maneira de desapertar: era cair no mangue. No mangue não se paga casa, come-se caranguejo e anda-se quase nu. O mangue é um paraíso. (CASTRO, 1938, p. 26)

É claro, esse paraíso não possui, como adverte Josué, o "cor-de-rosa ou o azul" do paraíso celeste, antes predominando ali apenas a cor negra da lama, mas ainda assim um paraíso para aqueles refugiados. Nesse momento, entra em cena o segundo personagem da saga, emergindo das águas e que também desfruta desse éden:

Os mangues do Capiberibe são o paraíso do caranguejo. Se a terra foi feita p'ro homem, com tudo de bem servi-lo, também o mangue foi feito especialmente p'ro caranguejo. (op. cit., p. 27).

A seguir, numa passagem tão límpida e enxuta quanto coerente e precisa, Josué principia o estabelecimento de um raciocínio que, ao juntar os dois protagonistas, articula ao mesmo tempo homem, meio e sociedade: "Tudo aí é, foi ou está para ser caranguejo, inclusive a lama e ou homem que vive nela" (op. cit.).

Prossegue o autor, desta vez ampliando uma pouco mais a escala e, por conseguinte, construindo todo o ciclo da tragédia da família:

A lama misturada com urina, excremento e outros resíduos que a maré traz, quando ainda não é caranguejo, vai ser. O caranguejo nasce nela, vive nela. Cresce comendo lama, engordando com as porcarias dela, fazendo com a lama a carninha branca de suas patas e a geleia esverdeada de suas vísceras pegajosas. Por outro lado, o povo daí vive de pegar caranguejo, chupar-lhe as patas, comer e lamber os seus cascos até que fiquem limpos como um copo. E com a sua carne feita de lama fazer a carne de seu corpo e a carne do corpo de seus filhos. (op. cit., p. 27).

O epidemiologista Melo Filho (2003) introduz uma interessante questão quando analisa a expressão homem-caranguejo à qual, por conta do movimento MangueBeat ${ }^{11}$, ficou popularmente associada a figura de Josué de Castro, procurando ver nos escritos a gênese de uma metáfora. Aquele autor propõe tal gênese a partir da visão de dois elementos diferentes, dadas as espécies às quais pertencem - homens e caranguejos -, passando posteriormente a uma leitura onde uns e outros cada vez mais se assemelham ou, nas palavras do próprio Josué de Castro, um momento onde os homens se mimetizam, arrastando-se como caranguejos, agachando-se como caranguejos, "parados como os caranguejos na beira da água ou caminhando para

\footnotetext{
${ }^{11}$ O Mangue-Beat foi um movimento cultural surgido em Pernambuco em meados dos anos 1990 e que teve em Josué de Castro um forte influenciador principalmente através de sua figura mais luminosa, o vocalista Chico Science da Banda Nação Zumbi.
} 
trás como caminham os caranguejos" (CASTRO, 1967, p. 4). Por fim, Melo Filho (op. cit.) reconhece e configura o momento em que Josué estabelece uma intersecção entre os dois elementos, criando então uma nova espécie em seus escritos. Assim é que os caranguejos que já habitavam o mangue e os recémchegados, os homens, que também passam a viver no mesmo ambiente, num processo de convivência e aproximação, não mais se assemelham, mas transformam-se numa terceira coisa: "Seres anfíbios - habitantes da terra e da água, meio homens e meio bichos. Alimentados na infância com caldo de caranguejo: este leite de lama" (op. cit., p. 3).

De fato, é possível ser consoante a essa proposição, pois ao ler o romance Homens e caranguejos vamos acompanhando esta saga, assistindo ao leite dos caranguejos ir impregnando o corpo e a alma do menino João Paulo que protagoniza a história, até a tragédia findar de forma quase apoteótica com a chegada da "tempestade dos homens", que cuida de transformar João Paulo em caranguejo, fechando e recomeçando o ciclo. Na verdade, podemos inclusive ir além da proposta de Melo Filho (op. cit.), já que na constituição dessa irmandade, ou seja, na configuração do ciclo do caranguejo, Josué de Castro lança mão, inclusive, de seus conhecimentos sobre o funcionamento da flora local para falar também do povo que vive no mangue:

Parecia que a vegetação densa dos mangues com seus troncos retorcidos, com o emaranhado de seus galhos rugosos e com a densa rede de suas raízes perfurantes os tinha agarrado definitivamente como um polvo, enfiando tentáculos invisíveis dentro de sua pele, pelos olhos, pela boca, pelos ouvidos. (CASTRO, 1967, p. 2 e 3).

Reparemos que Josué em nenhum momento perde de vista o ciclo do caranguejo, já que desta vez serão os homens que terão seus ossos chupados:

E assim ficavam todos eles afogados no mangue, agarrados pelas ventosas com as quais os mangues insaciáveis lhes sugavam todo o suco de sua carne e da sua alma de escravos". (op. cit., p. 2 e 3).

Estamos, então, deixando de falar de um mimetismo e passando na verdade a assistir ao nascimento de uma simbiose entre homens e caranguejos, que termina por tornar indistinguíveis uns e outros. Uma associação inicialmente impensável, mas agora mutuamente "vantajosa" para os homens que se alimentam dos caranguejos e para os caranguejos que inicialmente comem os dejetos dos homens, mas que fatalmente irão um dia se alimentar dos homens que flutuam e se afundam nas águas do mangue. Em meio a uma relação tão visceral Josué vislumbra um novo 
personagem, nem crustáceo nem gente, um novo ser que irá demandar tanto o conhecimento do meio que o sustenta quanto da sociedade que o engendra.

\section{Conclusão}

Decantemos agora, então, os principais aspectos desta pequena parcela da produção de Josué de Castro e que aqui foi examinada mais em detalhe. Em primeiro lugar, parece-nos mister destacar o papel que a descrição acaba desempenhando na produção do geógrafo pernambucano. Esta necessidade, num primeiro momento, beira o truísmo dado a escola à qual Josué de Castro está ligado. Já destacamos que na época em que a produção deste autor alcançava seu momento mais brilhante, também brilhavam fortemente as influências da geografia francesa no mundo e em especial no Brasil. Sendo a mesma marcada pela figura de La Blache, não se poderia esperar outra postura que não a de valorização da descrição como traço típico daqueles que estavam dentro desta órbita. Ocorre, porém, que o relevo dado ao visível não significa, de modo algum, o alinhamento puro e simples a uma escola de pensamento, mas suscita o papel que a lapidação da explicação sob a forma da palavra escrita encontrou em Josué de Castro. Ou seja, vimos aqui que o próprio ato de descrição promoveu um trabalho meticuloso com a palavra e por vezes parece estar irmanado com outro ato, o da descoberta, já que este trabalho de lapidação acabava também propiciando (ou até mesmo exigindo) que se desvelassem os recônditos da realidade conflagrada.

Seguindo estes princípios, a descrição deixa de ser, assim, mera característica dos estudos de Josué de Castro para se converter em atributo de sua proposta de análise. Um exemplo muito claro foi por nós divisado através do aproveitamento da visão para além do mero registro do visível, quando o autor propõe diferentes ângulos para o estudioso se apropriar, igualmente, de diferentes cidades. Notemos que esta proposta não é um devaneio, uma curiosidade advinda do pensamento do escritor, tal como o entendimento mais afoito poderia traduzir, senão um procedimento advindo da disciplina de um estudioso que cuida de se aproximar da melhor forma de seu objeto de análise, aproveitando-se também de um curioso jogo de escalas ${ }^{12}$, pois que diferentes ângulos resultam, neste caso, também em diferentes ordens de grandeza. Não fosse isso, não estaria esta proposta contida no estudo de sua célebre tese de cátedra que abordou os fatores de localização do Recife.

Outro exemplo desta relação profícua, onde as descrições do escritor e do cientista se confundem, pode ser obtido através da abertura de Josué de Castro às diversas fontes de informação no sentido de estas subsidiarem uma reflexão sumamente enriquecida. Como destacamos neste estudo, a recusa de Josué ao pensamento mais obtuso não se dava apenas quando dispunha de diferentes visões

${ }^{12}$ Tomamos esta expressão emprestada de Ribeiro (2010), que a utiliza para analisar a obra de La Blache. 
provindas dos campos mais diversos das ciências, mas igualmente quando ia a campo e mantinha o corpo e o espírito abertos às mais diversas fontes de informação. As cores de Recife enaltecidas pelo inconfundível reflexo do sol nas águas de seus rios, as alegrias e tristezas do povo, o perfume provindo da culinária e o cheiro de água podre emanado do mangue, as canções contidas nos folguedos populares, nada parece escapar à percepção de Josué, que como qualquer brilhante escritor transita pelas ruas de Recife. Este trânsito se dá no sentido de absorver o caldo provindo da cultura e do espaço urbano de Recife, daí a transdisciplinaridade contida no cientista e que lhe facultou ser discutido para muito além das cercanias da Geografia ou da Medicina. É da autoria de Josué o primeiro inquérito sobre "as condições de vida das classes operárias no Nordeste" ${ }^{\text {13 }}$ (1937), onde o tratamento estatístico dos dados é por demais similar aos trabalhos que se seguiriam sobre o mesmo tema provindos do IBGE. Ao mesmo tempo, a leitura de boa parcela da obra de Josué nos lembra também os trabalhos de cunho descritivos que haviam sido realizados na França no início do século $\mathrm{XIX}^{14}$, ou a Situação da classe trabalhadora na Inglaterra de Engels, produzido em 1845.

Chegamos ao fim deste caminho de forma muito parecida com a descrição que Josué de Castro faz da trajetória percorrida pelo rio Capibaribe. Da mesma maneira tímida que o curso d'água inicia sua jornada no semiárido pernambucano e o corta até o Atlântico percorrendo quase 300 quilômetros, também nos armamos da mesma despretensão para incursionarmos no pensamento de um gigante. Fomos nos deixando levar, percolando entre os meandros da escrita de Josué para melhor no encharcarmos com seu pensamento. Assim como o Capibaribe, que vai visitando diferentes municípios no mesmo espaço nordestino, também assistimos à alternância entre o cientista e o literato sem conseguirmos distinguir muito exatamente onde acabava um e se iniciava outro. Curiosamente, da mesma forma que Josué descreveu homens e caranguejos, e no próprio ato da descrição não se privou de se assombrar com o que se descortinava à sua frente, também nós nos fizemos a descoberta de um ser simbiótico. Nele cientista e escritor convivem também num ciclo, desta vez benfazejo, onde um se alimenta do outro mas onde ambos saem nutridos resplandecendo em vigor na escrita. Também que, da mesma maneira que o Capibaribe, fomos carregando uma parte de cada lugar que visitamos ou, neste caso, dos estudos que Josué nos coloca à disposição, e, como o rio que arrasta uma parcela do solo com seus minerais e os deposita na sua foz, fomos impregnados com estes conhecimentos que nos auxiliaram a iniciar a exploração das camadas que compõem esse desaguadouro. Ainda que a angústia e o inconformismo sejam a marca da escrita de Josué, é certo que o manancial de suas ideias permanece fértil

\footnotetext{
${ }^{13}$ Estudo realizado em 1932 mas só publicado em 1935. Para este trabalho utilizamos a versão que é publicada em 1937 constante em Documentário do Nordeste cuja segunda edição é de 1959.

${ }^{14}$ Ainda sobre tais trabalhos e sua característica descritiva, ver Milléo (2005).
} 
como um solo que sofreu a deposição de muitas camadas de minerais e nutrientes, trazidos no curso da água.

\section{Referências}

ANDRADE, Manoel Correia de. (2003) Uma releitura crítica da obra de Josué de Castro. In: et al. Josué de Castro e o Brasil. São Paulo, SP: Editora Fundação Perseu Abramo, p. 73-82.

ANTUNES, Ricardo. (2007) Adeus ao trabalho? São Paulo: Editora Cortez e Editora da UNICAMP.

CASTRO, Josué de (1959). Um ensaio de geografia urbana: a cidade do Recife. Recife, PE: Editora Fundação Joaquim Nabuco, 2013.

1959. . (1937). Documentário do Nordeste. $2^{\mathrm{a}}$ ed. São Paulo: Editora Brasiliense,

. (1946). Geografia da fome. $6^{a}$ ed. São Paulo: Editora Brasiliense, 1959. (1957). Ensaios de geografia humana. $4^{\text {a }}$ ed. São Paulo: Editora Brasiliense,

1966.

. (1967). Homens e caranguejos. Rio de Janeiro: Editora Bertrand Brasil, 2003. . (1984). Fome, um tema proibido: últimos escritos de Josué de Castro. $2^{\mathrm{a}}$ ed.

Petrópolis, RJ: Editora Vozes.

CLAVAL, Paul. (2010) Terra dos homens: a Geografia. São Paulo: Editora Contexto. CLOZIER, René. (1943)História da geografia. Sintra, Portugal: Editora Publicações Europa-América Ltda.

COLLOT, Michel. (2013) Poética e filosofia da paisagem. Rio de Janeiro: Editora Oficina Raquel.

DUPAS, Gilberto (2006) O mito do progresso ou o progresso como ideologia. São Paulo: Editora UNESP.

ENGELS, Friedric (1845). A situação da classe trabalhadora na Inglaterra. Lisboa: Editorial Presença/Martins Fontes, 1975.

FREYRE, Gilberto (1936). Sobrados e mocambos. Rio de Janeiro: Editora Record, 2000.

GIDDENS, Anthony; BECK, Ulrich; LASH, Scott (1994). Modernização reflexiva. São Paulo: Editora UNESP, 1997.

HABERMAS, Jurgen. (1968) Técnica como ciência e como Ideologia. Lisboa,Portugal: Editora Edições 70.

LA BLACHE, Paul Vidal (1913). As características próprias da Geografia. In:

CHRISTOFOLETTI, Antonio. (1985) Perspectivas da Geografia. São Paulo: Editora DIFEL, p. 37-48.

LYOTARD, Jean-François (1979). O pós-moderno. $3^{\text {a }}$ ed. Rio de Janeiro: Editora José Olympio, 1990. 
MANÇANO, Bernardo; PORTO-GONÇALVES, Carlos Walter (Orgs.). (2000) Josué de Castro: vida e obra. São Paulo: Editora Expressão Popular.

MARANDOLA JR, Eduardo; GRATÃO, Lúcia Helena Batista (Orgs.). (2010)

Geografia e Literatura: ensaios sobre geograficidade, poética e imaginação. Londrina: EDUEL.

MARTINS, José de Souza. (2014) Uma sociologia da vida cotidiana. São Paulo: Editora Contexto.

MELO FILHO, Djalma Agripino de. (2003) Uma hermenêutica do ciclo do caranguejo. In: ANDRADE, Manoel Correa de et al. Josué de Castro e o Brasil. São Paulo, SP: Editora Fundação Perseu Abramo, p. 61-72.

MILLÉO, José Carlos. (2005) A utilização dos indicadores sociais pela Geografia: uma análise crítica. Tese de doutorado. Niterói: Universidade Federal Fluminense.

Disponível em: $<$ http://www.bdtd.ndc.uff.br/tde_busca/index.php $>$.

MONTEIRO, Carlos Augusto Figueiredo. (2002) O mapa e a trama. Florianópolis, SC: Editora UFSC.

NISBET, Robert. (1980) História da ideia de progresso. Brasília: Editora Instituto Nacional do Livro e UNB, 1985.

RIBEIRO, Guilherme. Interrogando a ciência: a concepção vidaliana da Geografia.

Revista Confins [On-line], n. 8, 2010. Disponível em: <http://confins.revues.org/6295;

DOI: 10.4000/confins.6295>.

SALES, Teresa. (2014) João Cabral \& Josué de Castro: conversando com o Recife. São Paulo: Editora Cortez.

SANTOS, Milton. (1996) A natureza do espaço. São Paulo: EDUSP, 2002.

WEBER, Max. (1896) As causas sociais do declínio da cultura antiga. In: COHN, Gabriel. Weber. (2004) $7^{\text {a }}$ ed. São Paulo: Ática, p. 37-57. Coleção “Grandes Cientistas Sociais".

ZAIDAN FILHO, Michel. (2003) Representações sociais da miséria no Nordeste. In:

ANDRADE, Manoel Correa de et al. Josué de Castro e o Brasil. São Paulo, SP:

Editora Fundação Perseu Abramo, p. 83-88.

Data de submissão: 05/09/2016.

Data de aceite: 20/12/2016. 